\title{
O cheiro como informação no design de embalagens: um estudo de produtos fragrantes.
}

The smell as information in packaging design: a study of fragrant products.

\author{
Camila Assis Peres Silva
}

perfume, design, embalagens, multissensorial, Brasil

\begin{abstract}
O presente trabalho discorre sobre a importância de se considerar as informações de natureza olfativa como um parâmetro nos projetos de embalagem. Para tanto, apresentamos os resultados de pesquisas realizadas nos últimos anos no âmbito do design de embalagens de produtos fragrantes, especificamente os perfumes. Com um efeito altamente subjetivo sobre seu usuário, nos questionamos: qual seria a função de um perfume? E nos questionamos também: Qual seria a contribuição do design de embalagens para um projeto dessa natureza? Afinal, o franco crescimento do mercado de perfumaria brasileiro certamente não se deve apenas aos diferentes fatores de ordem econômica, tecnológica e cultural. 0 design tem a sua contribuição para o sucesso desse segmento de mercado. Até porque o design perpassa por todos esses fatores. Nossa hipótese é de que ao dar diferentes identidades aos diferentes perfumes, o design se torna fundamental para o bom desempenho desse mercado. Dentre as várias abordagens de um projeto de embalagens para perfumes, chamamos a atenção nesse trabalho para a importância da representação visual dos cheiros. Uma vez conhecendo a fragrância antes de projetar, o designer irá dispor de mais recursos para criar. Portanto, nosso percurso metodológico compreendeu na investigação e no entendimento do processo de olfação, seguido de levantamento bibliográfico acerca de experimentos realizados nos campos da psicologia e da percepção multissensorial, e finalmente na realização de experimentos realizados com usuários e perfumes brasileiros.
\end{abstract}

\section{perfume, design, packaging, multisensory, Brazil}

\begin{abstract}
This paper discusses the importance of considering olfactory information as a parameter in packaging designs. To do so, we present the results of research carried out over the past years in the field of packaging design of fragrant products, specifically perfumes. With a highly subjective effect on its user, we wonder: what would be the function of a perfume? And we also wondered: What would be the contribution of packaging design to such a project? After all, the frank growth of the Brazilian perfumery market is certainly not only due to the different economic, technological and cultural factors. Design has its contribution to the success of this market segment. That is due to the fact that design goes through all these factors. Our hypothesis is that by giving different identities to the different perfumes, the design becomes fundamental for the good performance of this market. Among the various approaches of a packaging design for perfumes, we draw attention in this work to the importance of the visual representation of the smells. Once you know the fragrance before designing, the designer will have more features to create. Therefore, our methodological course comprised the investigation and understanding of the olfaction process, followed by a bibliographical survey about experiments carried out in the fields of psychology and multisensory perception, and finally in the accomplishment of experiments performed with Brazilian users and perfumes.
\end{abstract}

\section{Introdução: o cheiro como informação}

O cheiro - sensação que se manifesta através do sentido do olfato - é essencial para a sobrevivência dos homens bem como das diferentes espécies de seres vivos. Trata-se de uma importante ferramenta para o reconhecimento de parentes, para a busca de companheiros reprodutivamente disponíveis e para a localização da comida. Apesar disso, a capacidade de comunicação que um cheiro possui foi sendo preterida, ao longo dos anos, em prol da linguagem visual e sonora. Ao desenvolver a fala e a escrita, o homem distanciou-se dos demais animais na maneira de se comunicar. Apesar disso, o cheiro, ainda que inconscientemente, não deixou de exercer influência nas relações dos homens na sociedade.

\author{
Anais do 9 CIDI e 9 CONGIC \\ Luciane Maria Fadel, Carla Spinillo, Anderson Horta, \\ Cristina Portugal (orgs.) \\ Sociedade Brasileira de Design da Informação - SBDI \\ Belo Horizonte | Brasil | 2019 \\ ISBN 978-85-212-1728-2
}

Proceedings of the 9th CIDI and 9th CONGIC

Luciane Maria Fadel, Carla Spinillo, Anderson Horta, Cristina Portugal (orgs.)

Sociedade Brasileira de Design da Informação - SBDI Belo Horizonte | Brazil | 2019

ISBN 978-85-212-1728-2 
Estabelecemos uma relação de positividade ou de negatividade em relação ao cheiro sob influência da experiência passada. Um cheiro costuma parecer bom quando nos é familiar (Wolfe et al., 2012, p. 420) e ruim quando não é familiar. Quando ruim, tendemos a repeli-lo por nos parecer algo perigoso. Do contrário, um bom cheiro pode ser um convite à aproximação.

Os cheiros são recebidos e processados pelo sistema límbico, responsável por regular os impulsos primitivos e coordenar as funções sensoriais e sexuais. Portanto, a sensação do cheiro está diretamente relacionada ao desejo sexual e ao comportamento emocional (Malnic, 2008 , p. 18). Ainda que não seja nossa principal fonte de comunicação, o cheiro ativa a memória e é capaz de evocar percepções que talvez nenhuma imagem ou texto fosse capaz fazer. Nos dias atuais, o cheiro pode servir como uma grande ferramenta para despertar sensações e tornar as experiências de consumo memoráveis. Martin Lindstrom (2012) argumenta a importância de trabalhar os diferentes sentidos em uma marca e traz exemplos do bom uso de estímulos olfativos. Para o autor, 'cada sentido pode ser influenciado para construir uma marca melhor, mais forte e mais duradoura' e este trabalho 'não pode ser feito de forma isolada', sendo importante que haja uma sinergia entre as várias formas de sensibilizar o consumidor (Lindstrom, 2012, p. 108). Nesse sentido corroboramos com o autor da literatura Patrick Süskind (2001, p. 155) quando ele diz que as pessoas até poderiam fechar os olhos ou tapar seus ouvidos para escapar daquilo que não Ihes interessa. Mas elas não poderiam escapar à fragrância, afinal ela é companheira da respiração, da qual necessitamos para viver. Ele acrescenta que a fragrância atinge a nossa essência, e aquele que dominasse as fragrâncias dominaria o coração dos homens. Ousamos, portanto, dizer que, na atual sociedade de consumo, aqueles que souberem se apropriar dos cheiros em benefício dos seus projetos estarão mais próximos dos corações de seus consumidores.

Os cheiros não apenas são fundamentais no nosso cotidiano como estão integrados com os demais sentidos. Por mais que algumas instituições ainda abordem a dinâmica dos sentidos separadamente, nossa interação com o mundo não se dá de forma isolada, através de cada um dos sentidos. É na inter-relação de todos os sentidos que compreendemos a realidade: 'o próprio pensamento é intersemiótico e essa qualidade se concretiza nas linguagens e sua hibridização' (Plaza, 1987, p. 30). É com base nessa premissa que propomos a integração do conhecimento dos cheiros com a prática do design.

O presente trabalho abordará a questão dos cheiros aplicados a projetos de embalagem de perfume. Em um limiar entre a necessidade básica e o desejo, o perfume exerce um poder especial sobre homens e mulheres. Dele não dependemos para o asseio básico e diário, porém grande parte dos produtos de higiene e de cuidados pessoais é perfumada. O Brasil apresenta um grande mercado de perfumaria, tendo sido considerado um dos maiores mercados de consumo do mundo (ABIHPEC, 2017). Diante desse cenário, há de se pensar no potencial dos cheiros em comunicar, tal como nas contribuições que o design de embalagens pode trazer. Sabe-se também que o primeiro contato com um perfume é através da sua embalagem. Sendo a fragrância um aspecto da escolha no momento da compra, o designer deve entender melhor os estímulos olfativos, de modo a ser capaz de traduzi-los para a linguagem visual.

Dentre os diferentes elementos da linguagem visual, abordaremos neste trabalho o uso das cores e das formas em frascos de perfumes em sua capacidade de representar os cheiros. Isto é, em sua capacidade de antecipar, através de um estímulo visual, a sensação provocada pelo estímulo olfativo. Vale ressaltar, que identificar visualmente um cheiro não é uma tarefa muito fácil. Além de o cheiro evocar percepções que variam de indivíduo a indivíduo, sabe-se que os humanos possuem dificuldades de visualizá-los e verbalizá-los. Podemos detectar e discriminar centenas de odores, mas reconhecê-los não é tão fácil (Wolfe et al., 2012). Apesar disso, pesquisadores de diferentes universidades e empresas têm investigado o campo de correspondências entre os sentidos. Resultados positivos obtidos nessas pesquisas nos encorajaram a investigar o campo.

\section{Abordagem multissensorial: uma revisão bibliográfica}

Em busca por pesquisas que analisassem a interação e a correspondência entre os sentidos identificamos o uso de termos como multissensorial (Joutsela, 2010; Spence \& Piqueras- 
Fiszman, 2012; Lindstrom, 2012), cross-modal (Macpherson, 2011), design sinestésico ${ }^{1}$ (Haverkamp, 2013). O termo sinestesia também tem sido muito associado ao design. Por utilizarmos a psicologia experimental como um dos pilares para essa pesquisa, mantivemos 0 uso do termo multissensorial, em vez de sinestesia. No que tange a abordagem multissensorial aqui proposta, ainda não existe literatura que forneça correspondências concretas entre os estímulos olfativos e os visuais. No entanto, identificamos pesquisas, tanto no segmento de cosméticos (Kim, 2008; Moeran, 2011) quanto em demais áreas que envolvem odores ${ }^{2}$ (Gilbert et al., 1996; Demattè et al., 2006; Spector \& Maurer, 2012; Morrot et al., 2001; Hanson-Vaux et al., 2013), com o objetivo de identificar tais correspondências. Apesar da dificuldade de construir um vocabulário consistente de fragrâncias, os resultados de tais pesquisas demonstram que as cores podem influenciar os odores. Assim como formas geométricas podem estabelecer relações com determinados cheiros.

A pesquisadora coreana Yu-Jin Kim (2008) investigou a relação entre os diferentes tons de cores e as intensidades de uma fragrância. Com base em experimentos realizados, Kim pode confirmar interações entre a visão e o olfato na perfumaria. Kim realizou um experimento com mais de 200 perfumes, tendo obtido associações de cores e odores semelhantes às cores reais dos perfumes. Cada uma das fragrâncias foi analisada três vezes, de forma a capturar o cheiro em seus três estágios, notas de saída, notas de corpo e notas de fundo ${ }^{3}$. Os intervalos estabelecidos foram de 0, 2 e 30 minutos. Para isso, a escala de cores apresentada variava em matizes e tons. Como resultado, observou-se que as notas de fundo, menos voláteis, foram associadas a tons de cores mais claros que aquelas mais voláteis, notas de saída. Kim acredita que a combinação apropriada de cores e odores eleva o interesse dos consumidores pelos perfumes, podendo influenciar em suas decisões de compra.

O campo da perfumaria também foi analisado pelo pesquisador canadense Brian Morean, professor de antropologia empresarial. Em sua análise de mais de 250 anúncios de perfumes Moeran (2011) buscou investigar a linguagem e a representação visual de perfumes na publicidade. O autor não identificou uma consistência no uso de cores para representação de perfumes. Porém, identificou que anúncios de perfumes florais utilizam mais as cores rosa e azul do que as demais categorias, assim como perfumes da família oriental tendem a usar mais as cores pretas e roxas, e muito pouco a branca. Para Morean, a cor é um importante guia na escolha de fragrâncias.

Um grupo de pesquisadores da empresa Givaudan-Roure Fragrances realizou dois tipos de experimentos com consumidores em Nova Jersey (Estados Unidos), de forma a encontrar correspondências entre os estímulos olfativos e os visuais (Gilbert et al., 1996). Como métodos para os experimentos eles usaram um questionário para relacionar cheiros e cores (anteriormente utilizado por Rader e Tellegen, 1987) e as fichas de cores de Munsell, para serem associadas aos estímulos olfativos. Os autores confirmaram a possibilidade de associar cores a odores, apesar da dificuldade que as pessoas têm de verbalizar sua percepção de um odor. Os autores apontam para uma possível relação entre tonalidades de cores e intensidades de fragrâncias. Esses resultados atraíram o interesse de pesquisadores do Departamento de Psicologia Experimental da Universidade de Oxford (Demattè et al., 2006), que utilizaram o teste de associação implícita (IAT, Implicit Association Test) para confirmar as correspondências entre os sentidos verificadas, dez anos antes, por Gilbert e seus colaboradores (1996). O estudo recente confirma a existência da relação, porém não investiga a origem da associação. Os pesquisadores de Oxford sugerem que o estabelecimento de tais associações é proveniente de uma experiência vivenciada pelas pessoas. Em seus experimentos com odores de menta e morango, houve pessoas que diziam que os odores lembravam pasta de dente e chiclete, respectivamente.

\footnotetext{
1 Traduzido de synesthetic design.

${ }^{2}$ É chamado de odor uma cheiro agradável, uma fragrância (cosméticos) ou um aroma (alimentos).

${ }^{3}$ Nota olfativa é a maneira com a qual os ingredientes de um perfume se organizam. "As notas olfativas de um perfume se dividem em notas de saída ou de cabeça, que são as mais voláteis (as primeiras a serem percebidas), seguidas por notas de corpo ou de coração, que personificam o perfume e, finalmente, as notas de fundo ou de base, que como o próprio nome sugere, é a base de uma fragrância. Estas últimas são notas de maior peso e durabilidade" (Silva, 2012).
} 
Pesquisadores do Departamento de Psicologia, Neurociência e Comportamento da McMaster University, Canada (Spector \& Maurer, 2012) também realizaram experimentos para identificar associações de cores e texturas a odores. Os autores argumentam que o olfato pode interagir de forma sistemática com outras modalidades sensoriais, além do paladar. Acreditando na consistência de uma associação entre cores e odores, Spector e Maurer repetiram experimentos com quatro dos odores utilizados em 1996 por Gilbert e demais pesquisadores, tendo obtido resultados similares. Os experimentos foram realizados com 78 adultos não sinestésicos de idade de 17 a 44 anos, sendo oito deles homens. Os pesquisadores utilizaram 22 odores, dos quais 14 eram familiares e 8 não familiares. Os participantes foram orientados a não identificar os odores, mas apenas cheirá-los e tentar descobrir uma cor e uma textura que pudessem ser associados a tal cheiro. Além de estabelecer associações entre cores e odores e texturas e odores, os participantes foram questionados sobre a dificuldade de estabelecer tais relações sensoriais devendo pontuar conforme uma escala de 1 a 7 onde 1 era fácil e 7 difícil. Além disso, deveriam pontuar de 1 a 7 se esse tipo de associação fazia sentido, onde 1 significava fazer sentido e 7 sem sentido. A maioria dos participantes disse ter tido dificuldade de estabelecer as associações. Apesar disso, eles disseram fazer sentido tal abordagem sensorial. Fato que estimula o desmembramento de pesquisas no campo.

A relação entre cores e odores também é de interesse de enólogos. Pesquisas realizadas com especialistas em vinhos (Morrot et al., 2001) apontam para a existência de uma ilusão perceptual, onde as cores influenciam a percepção de odores. O odor do vinho branco colorido artificialmente com pigmento vermelho foi percebido como odor de vinho tinto em pesquisa com 54 provadores especialistas. É possível que tal resultado seja devido ao fato dos degustadores saberem que determinados vinhos recebem a coloração conforme seus ingredientes. $O$ vinho rosé, por exemplo, tem sabor de frutas rosadas tais como a framboesa e a groselha. De todo modo, a pesquisa reforça as correspondências entre os sentidos, conforme já apontado por outros pesquisadores.

Finalmente, com relação às correspondências entre formas e cheiros, foi identificado um experimento realizado na Universidade de Oxford (Hanson-Vaux et. al, 2013). Os pesquisadores utilizaram os estudos acerca do efeito Bouba/Kiki (também conhecido como Maluma/Takete), para associar odores a formas angulares e arredondadas. Utilizamos esse experimento como referência para a formulação de uma das perguntas dos experimentos realizados. Sobre o efeito Bouba/Kiki, o detalharemos, mais adiante, neste capítulo na seção de metodologia. Quanto ao experimento aqui analisado, o mesmo se realizou em Oxford e consistiu em solicitar que os participantes associassem odores utilizados na produção de vinho com formas mais ou menos angulares. Como resultado, foram obtidas associações do odor de limão (lemon) e do cedro (cedar) à forma angular, e da violeta (violet) e da baunilha (vanilla) a formas arredondadas. Esses resultados nos fazem questionar se os perfumes que contém tais ingredientes podem ser associados às mesmas formas. O perfume cítrico estaria associado com formas angulares, por conter em sua fórmula ingredientes como limão? E os florais estariam associados a formas arredondadas?

As diferentes pesquisas que aqui apresentamos serviram, não apenas como um endosso para prosseguirmos na investigação de nossas hipóteses, como também nos embasaram na formulação das perguntas utilizadas nos experimentos que realizamos. Nas páginas a seguir, detalhamos os métodos e os materiais para a investigação das cores e das formas dos cheiros na busca por correspondências entre os sentidos do olfato e da visão no design de frascos para perfumes.

\title{
3 As cores e as formas dos cheiros: experimentos sensoriais
}

\author{
Materiais e métodos
}


Nos meses de janeiro e março de 2015, durante pesquisa de doutorado, realizamos experimentos sensoriais no Laboratório de Análise Sensorial (figura 2) da Faculdade de Ciências Farmacêuticas da Universidade de São Paulo (FCF/USP). O experimento consistiu na investigação das relações que os participantes estabeleceriam entre uma fragrância e alternativas de cores e de formas de embalagem a partir de uma estimulação olfativa às cegas. A fim de estudar quatro estímulos olfativos diferentes, selecionamos quatro perfumes comercializados no mercado e pertencentes às famílias olfativas cítrica, floral, amadeirada e oriental.

Figura 2: Cabines de análise sensorial onde foram realizados os experimentos.
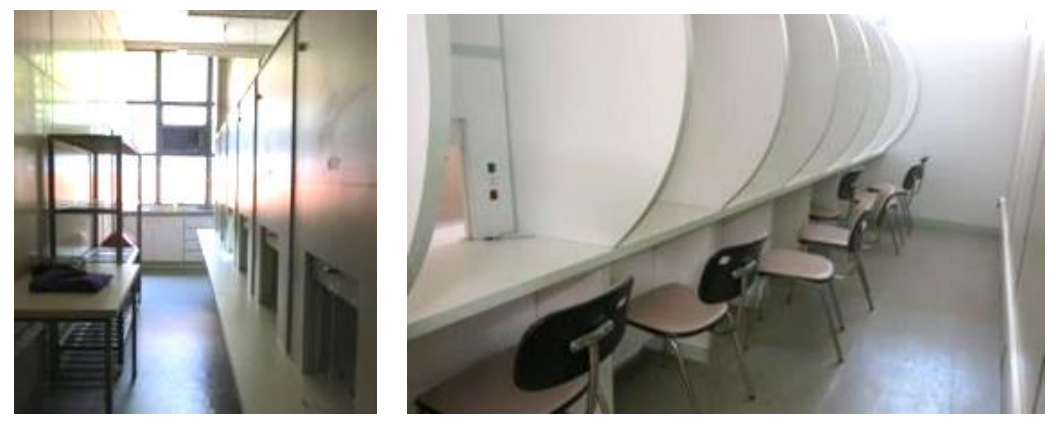

Priorizamos fazer uma investigação mais profunda para cada um dos quatro estímulos olfativos. Para isso, dividimos a pesquisa em oito sessões de experimentos, divididas em dois grupos. Um grupo (1) de pesquisas tinha como objetivo coletar associações dos cheiros com as cores e o outro grupo (2), coletar associações com formas de frascos e tampas de perfume. Dado o caráter exploratório da pesquisa, delimitamos o número mínimo de 30 participantes. Dada a localização do Laboratório, no Conjunto das Químicas da Universidade de São Paulo, a qualidade da amostragem sofreu influência, sendo esta majoritariamente de universitários das áreas de exatas e biológicas. Obtivemos o envolvimento voluntário de 345 de participantes, dentre os quais estudantes da graduação e da pós-graduação, bem como funcionários e visitantes da USP. É importante destacar que essa pesquisa não delimitou nenhum público específico. Não existiu intenção, através das amostras, de refletir dados de uma população específica.

A convocação dos participantes foi feita através de divulgação em cartaz no prédio da Faculdade de Ciências Farmacêuticas, no mesmo dia de realização dos experimentos. Como critério de inclusão foram consideradas aptas pessoas com mais de dezoito anos e sentidos da visão (das cores) e olfato normais, isto é, não deveriam apresentar nem daltonismo nem anosmia (perda completa ou parcial do olfato). Como critério de exclusão, não foram aceitas pessoas que apresentassem algum quadro clínico em que seus sentidos do olfato (ex. gripe, rinite, sinusite) ou da visão (ex. conjuntivite) estivessem comprometidos. Não apareceram voluntários com esse quadro. Com relação à visão de cores, apesar das alegações de normalidade, foi aplicado o teste de detecção de daltonismo antes da realização do experimento. Mesmo que fosse identificada alguma anormalidade, foi dada ao participante a possibilidade de prosseguir com a pesquisa. Os participantes que foram identificados como daltônicos tiveram seus dados computados, porém não entraram na análise. Por fim, os experimentos apresentaram um risco mínimo aos participantes, visto que foram utilizados perfumes comercializados regularmente no Brasil.

Os perfumes selecionados para análise pertencem à empresa $\mathrm{O}$ Boticário e a escolha da empresa foi devido à abrangência da mesma pelo território nacional. Vale destacar, no entanto, que a empresa não possuiu qualquer participação nessa pesquisa, não tendo colaborado para o desenvolvimento do trabalho aqui apresentado. Os perfumes foram todos selecionados na mesma concentração de desodorante colônia. O critério para seleção se baseou nas descrições que a empresa fornece em seu website oficial. O perfume Free foi selecionado para representar a família de cítricos; o Floratta in Rose, para representar a família de florais; o Malbec Duo, para representar a família dos amadeirados; e o Coffee Man Seduction, para representar a família dos orientais (figura 3). Para averiguar a percepção do participante com 
Silva, C.A.P. | O cheiro como informação no design de embalagens: um estudo de produtos fragrantes.

relação às cores (grupo 1), elaboramos uma cartela com 36 cores distribuídas de forma randomizada (figura 4). Para averiguar a percepção quanto à forma (grupo 2) selecionamos sete frascos de vidro da linha standard da empresa Wheaton (figura 5) e dez tampas plásticas da linha standard da empresa Incom (figura 6). Os frascos e as tampas foram classificados conforme formato pontiagudo, arredondado ou intermediário (figura 7).

Figura 3: Perfumes selecionados: Free, Floratta in Rose, Malbec Duo, e Coffee Man Seduction.

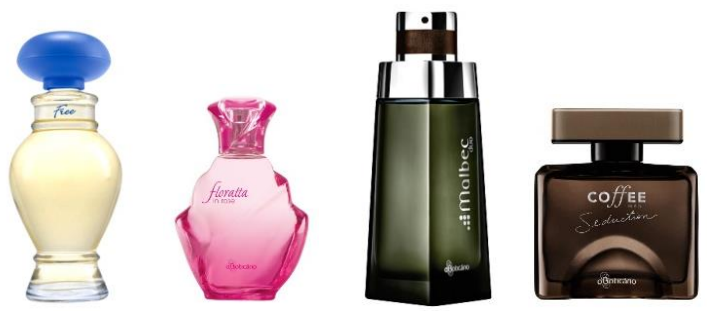

Figura 4: Lista das cores com respectivos códigos gerados a partir da técnica de randomização.

\begin{tabular}{|c|c|c|c|c|c|c|}
\hline & C & M & $Y$ & $\mathrm{~K}$ & NOME & CóDIGO \\
\hline \multirow{13}{*}{ 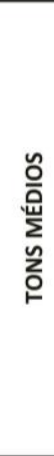 } & C100 & & & & CIANO & 681 \\
\hline & C100 & M50 & & & AZUL & 910 \\
\hline & C100 & M100 & & & AZUL VIOLETA & 713 \\
\hline & C50 & M100 & & & VIOLETA & 524 \\
\hline & & M100 & & & MAGENTA & 101 \\
\hline & & M100 & Y50 & & ROSA & 970 \\
\hline & & M100 & $Y 100$ & & VERMELHO & 889 \\
\hline & & M50 & $Y 100$ & & LARANJA & 307 \\
\hline & & & $Y 100$ & & AMARELO & 512 \\
\hline & $\mathrm{C50}$ & & $\mathrm{Y} 100$ & & AMARELO ESVERDEADO & 751 \\
\hline & C100 & & $\mathrm{Y} 100$ & & VERDE & 425 \\
\hline & C100 & & Y50 & & VERDE AZULADO & 508 \\
\hline & & & & $\mathrm{K} 50$ & CINZA & 192 \\
\hline \multirow{13}{*}{ 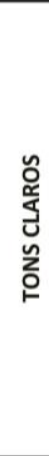 } & C50 & & & & CIANO 50\% & 983 \\
\hline & $\mathrm{C50}$ & M25 & & & AZUL 50\% & 503 \\
\hline & $\mathrm{C50}$ & M50 & & & AZUL VIOLETA 50\% & 638 \\
\hline & $\mathrm{C25}$ & M50 & & & VIOLETA 50\% & 864 \\
\hline & & M50 & & & MAGENTA 50\% & 499 \\
\hline & & M50 & Y25 & & ROSA 50\% & 321 \\
\hline & & M50 & Y50 & & VERMELHO $50 \%$ & 874 \\
\hline & & M25 & Y50 & & LARANJA 50\% & 663 \\
\hline & & & Y50 & & AMARELO 50\% & 764 \\
\hline & C25 & & Y50 & & AMARELO ESVERDEADO $50 \%$ & 515 \\
\hline & c50 & & Y50 & & VERDE 50\% & 431 \\
\hline & C50 & & Y25 & & VERDE AZULADO $50 \%$ & 725 \\
\hline & & & & Ko & BRANCO & 863 \\
\hline \multirow{13}{*}{ 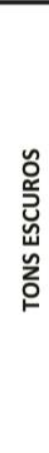 } & C100 & & & K50 & CIANO ESCURO & 486 \\
\hline & C100 & M50 & & K50 & AZUL ESCURO & 230 \\
\hline & C100 & M100 & & K50 & AZUL VIOLETA ESCURO & 576 \\
\hline & C50 & M100 & & K50 & VIOLETA ESCURO & 186 \\
\hline & & M100 & & K50 & MAGENTA ESCURO & 995 \\
\hline & & M100 & Y50 & K50 & ROSA ESCURO & 459 \\
\hline & & M100 & $Y 100$ & K50 & VERMELHO ESCURO (VINHO) & 976 \\
\hline & & M50 & $Y 100$ & K50 & LARANJA ESCURO (MARROM) & 123 \\
\hline & & & Y100 & K50 & AMARELO ESCURO & 624 \\
\hline & C50 & & $Y 100$ & K50 & AMARELO ESVERDEADO ESCURO & 483 \\
\hline & C100 & & $\mathrm{Y100}$ & K50 & VERDE ESCURO & 903 \\
\hline & C100 & & Y50 & K50 & VERDE AZULADO ESCURO & 817 \\
\hline & & & & $\mathrm{K} 100$ & PRETO & 741 \\
\hline
\end{tabular}

Figura 5: Frascos utilizados nos experimentos do grupo 2.

Anais do 9 Congresso Internacional de Design da Informação | CIDI 2019 
Silva, C.A.P. | O cheiro como informação no design de embalagens: um estudo de produtos fragrantes.

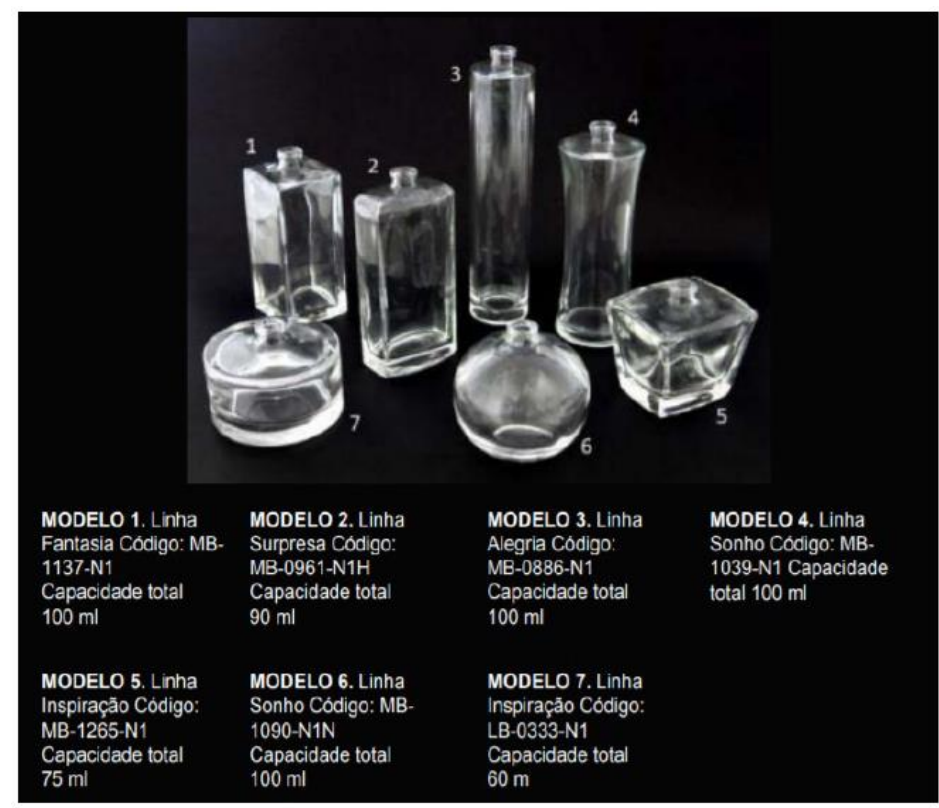

Figura 6: Tampas utilizados nos experimentos do grupo 2.

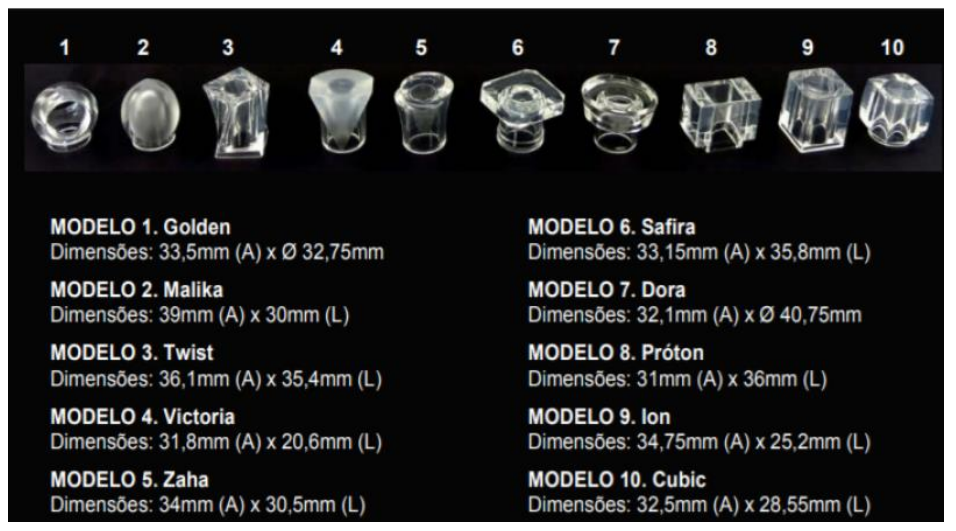

Figura 7: Classificação das embalagens quanto à forma.

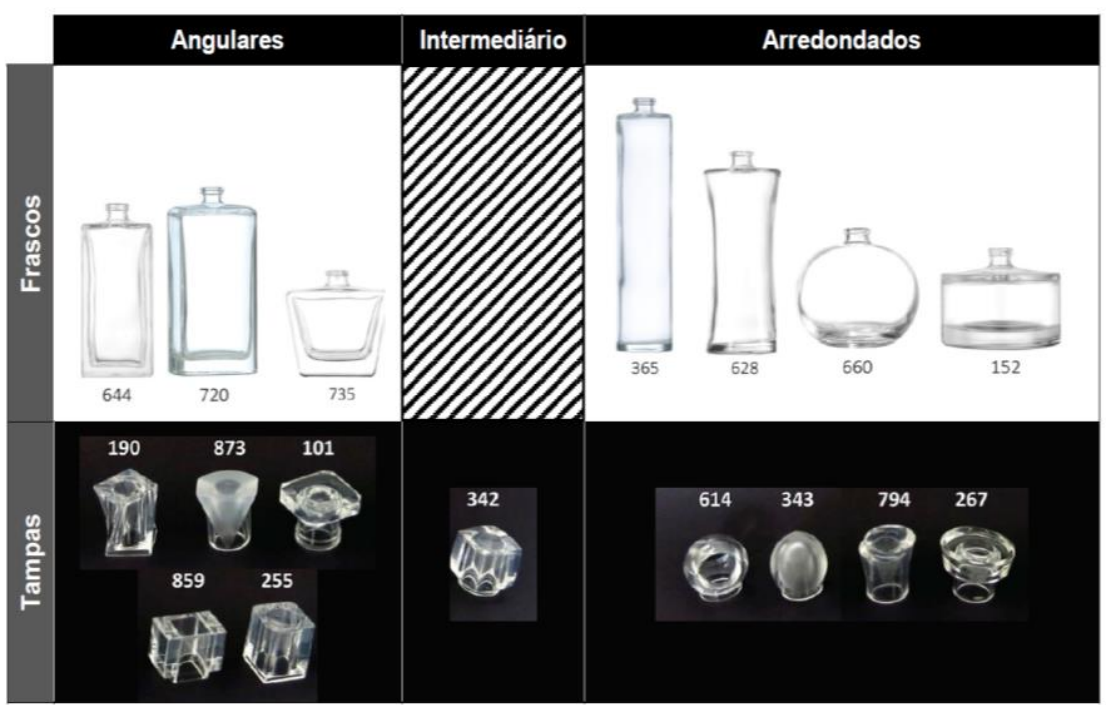

Anais do 9ํㅡㄹ Congresso Internacional de Design da Informação | CIDI 2019 
Utilizamos dois modelos de questionários, um para cada grupo. Nos experimentos do grupo 1 (cores e cheiros), cada participante foi indagado sobre qual seria a melhor cor para representar a fragrância experimentada (pergunta 1). O participante foi requisitado a informar o grau de dificuldade em se estabelecer tais associações (pergunta 2) e o quanto essa associação fazia sentido (pergunta 3). Foi também requisitado a informar o grau de familiaridade com os estímulos (pergunta 4) e o que a fragrância lhe fazia lembrar, caso fosse familiar (pergunta 5). Finalmente, foi requisitado a associar a fragrância a palavras: a pergunta 6 permitia uma resposta aberta; na pergunta 7 o participante deveria selecionar livremente palavras pré-estabelecidas (perguntas 6 e 7 ).

Nos experimentos do grupo 2 (formas e cheiros), as mesmas fragrâncias apresentadas na primeira parte do experimento foram novamente avaliadas, dessa vez, na busca de uma relação com frascos e tampas de perfume. O procedimento foi similar aos experimentos do grupo 1, sendo apenas eliminado o questionário de daltonismo. Tal como nos experimentos do grupo 1, o participante foi requisitado a informar o grau de dificuldade de se estabelecer associações entre os estímulos olfativo e visual e se isso fazia sentido para ele, assim como entre o grau de familiaridade com os estímulos e a associação com palavras. Esse experimento possuiu uma pergunta a mais, totalizando oito, e diferiu do questionário do grupo 1 apenas nas três primeiras perguntas, sendo as cinco últimas iguais. Em cada um dos oito experimentos realizados, o participante passou por quatro etapas:

- Etapa 1 - Contato inicial: Instruções básicas sobre o tema da análise sensorial foram fornecidas aos interessados que apareceram voluntariamente na porta do laboratório. Após concordar em participar, os candidatos foram encaminhados a uma das sete cabines do Laboratório de Análise Sensorial localizado na FCF/USP.

- Etapa 2 - Termo de Consentimento Livre e Esclarecido (TCLE): Uma vez acomodado na cabine, o participante recebeu duas vias do TCLE, o qual teve que ser lido, rubricado em todas as páginas e assinado ao final. O participante optou por ficar ou não com uma cópia e teve que entregar a outra via.

- Etapa 3 - Questionário preliminar: O participante recebeu um questionário (hábitos e dados pessoais) com sete perguntas. Além disso, aqueles que participaram dos experimentos do grupo 1 (cores) também receberam um teste de visão simplificado (6 cartelas) adaptado com base em livro original do Dr. Shinobu Ishihara (Ishihara, 1972, p. 4).

- Etapa 4 - Análise sensorial: Os participantes receberam uma tira olfativa com a fragrância a ser experimentada e um bloco com as perguntas. Além disso, para os experimentos do grupo 1, cada um recebeu também uma cartela de cores (figura 8); para os do grupo 2, os participantes receberam um kit com os frascos e tampas a serem analisados (figura 9 ).

Figura 8: Cartela de cores com questionário entregues aos participantes do grupo 1 de experimentos.

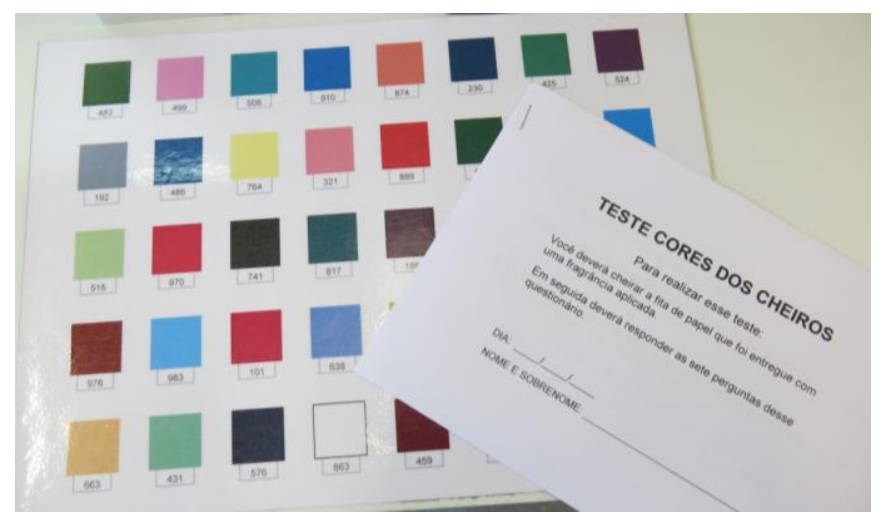

Figura 9: Kit de frascos e tampas entregue aos participantes do grupo 2. 


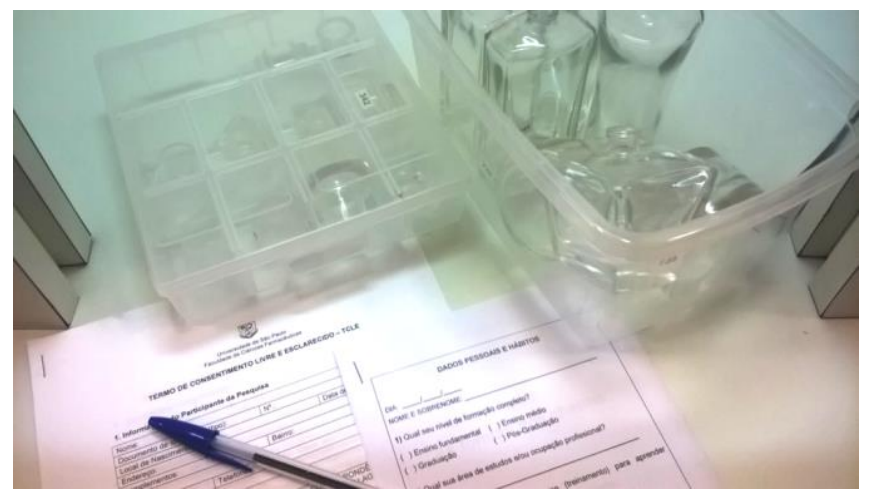

\section{Resultados e discussões}

Dentre os resultados obtidos na realização dos experimentos selecionamos, para discussão no presente artigo, as respostas das principais perguntas de cada experimento. Isto é, quais cores e formas melhor se relacionam aos cheiros dos perfumes. Apresentamos a seguir quatro tabelas com a porcentagem de respostas fornecidas para cada um dos quatro estímulos olfativos. As tabelas 1 e 2 apresentam as associações estabelecidas entre os cheiros e as cores. As tabelas 3 e 4, as associações estabelecidas entre os cheiros e as formas.

Tabela 1: Resultados das associações dos cheiros às cores organizadas por matizes.

\begin{tabular}{l|c|c|c|c} 
& $\begin{array}{l}\text { Perfume A } \\
\text { Cítrico }\end{array}$ & $\begin{array}{l}\text { Perfume B } \\
\text { Floral }\end{array}$ & $\begin{array}{l}\text { Perfume C } \\
\text { Amadeirado }\end{array}$ & $\begin{array}{l}\text { Perfume D } \\
\text { Oriental }\end{array}$ \\
\hline GRUPO 1: Azulados & $10 \%$ & $5 \%$ & $25 \%$ & $23 \%$ \\
\hline GRUPO 2: Violetas e Rosas & $13 \%$ & $\mathbf{5 3} \%$ & $20 \%$ & $30 \%$ \\
\hline $\begin{array}{l}\text { GRUPO 3 Avermelhados, } \\
\text { Alaranjado e Amarelos }\end{array}$ & $20 \%$ & $23 \%$ & $33 \%$ & $20 \%$ \\
\hline GRUPO 4: Esverdeados & $\mathbf{5 8} \%$ & $18 \%$ & $20 \%$ & $23 \%$ \\
\hline GRUPO 5: Neutros & $0 \%$ & $3 \%$ & $3 \%$ & $5 \%$ \\
\hline Total de respostas & $100 \%$ & $100 \%$ & $100 \%$ & $100 \%$ \\
\hline
\end{tabular}

Tabela 2: Resultados das associações dos cheiros às cores organizadas por níveis de claridade.

\begin{tabular}{l|c|c|c|c} 
& $\begin{array}{l}\text { Perfume A } \\
\text { Cítrico }\end{array}$ & $\begin{array}{l}\text { Perfume B } \\
\text { Floral }\end{array}$ & $\begin{array}{l}\text { Perfume C } \\
\text { Amadeirado }\end{array}$ & $\begin{array}{l}\text { Perfume D } \\
\text { Oriental }\end{array}$ \\
\hline Cores escuras & $30 \%$ & $5 \%$ & $\mathbf{5 2 , 5 \%}$ & $22,5 \%$ \\
\hline Cores medias & $32,5 \%$ & $25 \%$ & $15 \%$ & $15 \%$ \\
\hline Cores claras & $37,5 \%$ & $\mathbf{7 0 \%}$ & $32,5 \%$ & $\mathbf{6 2 , 5 \%}$ \\
\hline $\begin{array}{l}\text { Total de } \\
\text { respostas }\end{array}$ & $100 \%$ & $100 \%$ & $100 \%$ & $100 \%$ \\
\hline
\end{tabular}

Tabela 3: Resultados das associações dos cheiros às formas dos frascos.

\begin{tabular}{l|c|c|c|c} 
& $\begin{array}{l}\text { Perfume A } \\
\text { Cítrico }\end{array}$ & $\begin{array}{l}\text { Perfume B } \\
\text { Floral }\end{array}$ & $\begin{array}{l}\text { Perfume C } \\
\text { Amadeirado }\end{array}$ & $\begin{array}{l}\text { Perfume D } \\
\text { Oriental }\end{array}$ \\
\hline Frascos arredondados & $22,2 \%$ & $\mathbf{5 7 , 8} \%$ & $35,6 \%$ & $\mathbf{5 3 , 3} \%$ \\
\hline Frascos pontiagudos & $\mathbf{7 7 , 8 \%}$ & $42,2 \%$ & $\mathbf{6 4 , 4 \%}$ & $46,7 \%$ \\
\hline Total de respostas & $100 \%$ & $100 \%$ & $100 \%$ & $100 \%$ \\
\hline
\end{tabular}

Tabela 4: Resultados das associações dos cheiros às formas das tampas. 
Silva, C.A.P. | O cheiro como informação no design de embalagens: um estudo de produtos fragrantes.

\begin{tabular}{l|c|c|c|c} 
& $\begin{array}{l}\text { Perfume A } \\
\text { Cítrico }\end{array}$ & $\begin{array}{l}\text { Perfume B } \\
\text { Floral }\end{array}$ & $\begin{array}{l}\text { Perfume C } \\
\text { Amadeirado }\end{array}$ & $\begin{array}{l}\text { Perfume D } \\
\text { Oriental }\end{array}$ \\
\hline Tampas arredondadas & $28,9 \%$ & $\mathbf{4 8 , 9 \%}$ & $24,4 \%$ & $42,2 \%$ \\
\hline Tampas intermediárias & $11,1 \%$ & $17,8 \%$ & $17,8 \%$ & $6,7 \%$ \\
\hline Tampas pontiagudas & $\mathbf{6 0 , 0} \%$ & $33,3 \%$ & $\mathbf{5 7 , 8 \%}$ & $\mathbf{5 1 , 1 \%}$ \\
\hline Total de respostas & $100 \%$ & $100 \%$ & $100 \%$ & $100 \%$ \\
\hline
\end{tabular}

Com relação às associações dos cheiros às cores destacamos os resultados do experimento com o perfume Floratta in Rose, da família de florais. Apesar de comumente relacionado aos matizes vermelhos, rosas e violáceos (figura 10), os resultados obtidos no experimento apontam, além da mera associação ao matiz (figura 11), a correlação do perfume floral com cores claras (figura 12). Os dados obtidos na associação de palavras (figura 13) apontam uma possível relação entre a seleção de um matiz claro a partir de uma percepção de frescor e suavidade.

Figura 10: As cores dos cheiros segundo empresas de fragrâncias (Silva \& Mazzilli, 2014).

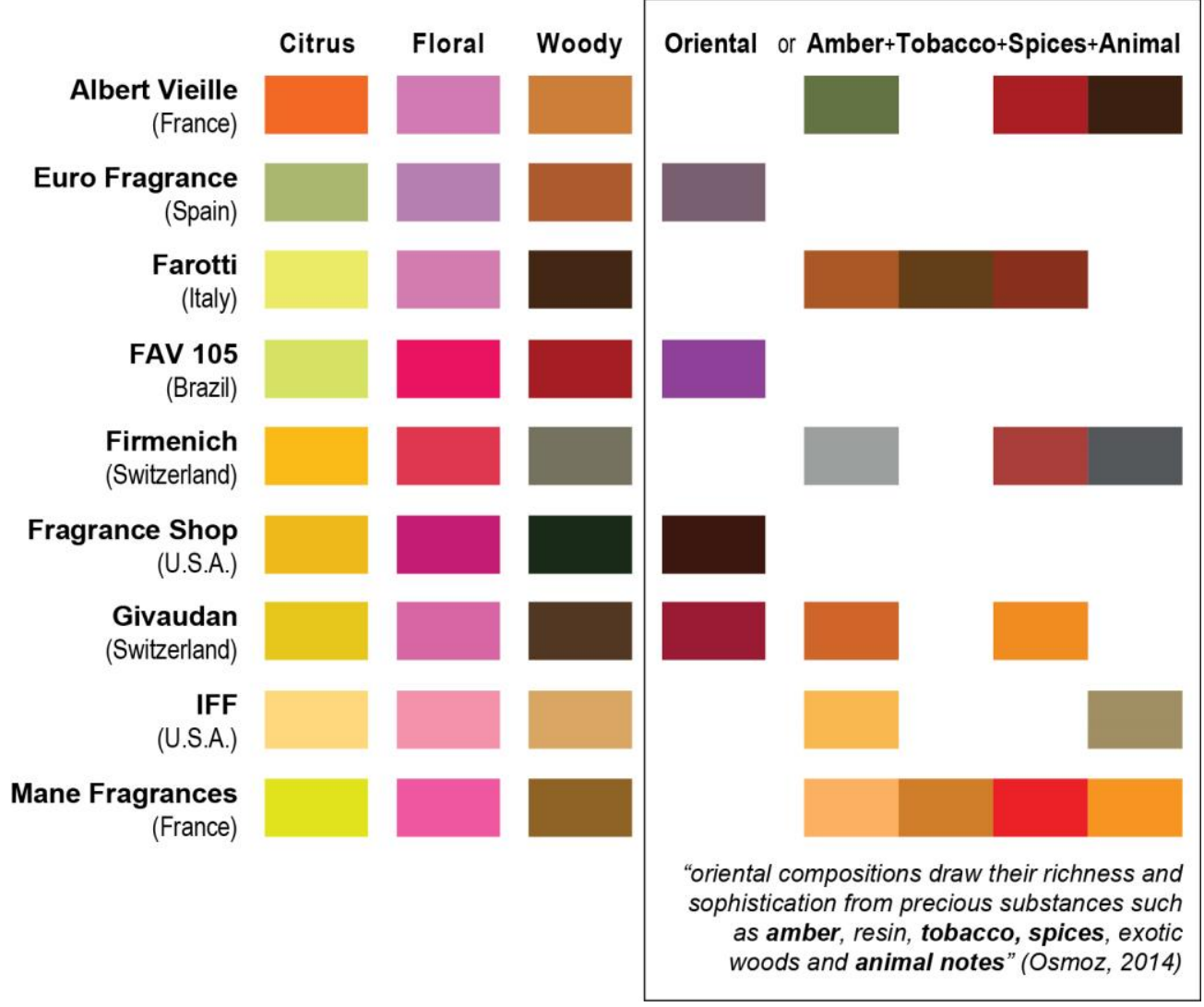

Figura 11: As cores indicadas para o perfume floral (Floratta in Rose). Ordenação das cores por matizes. 
Silva, C.A.P. | O cheiro como informação no design de embalagens: um estudo de produtos fragrantes.

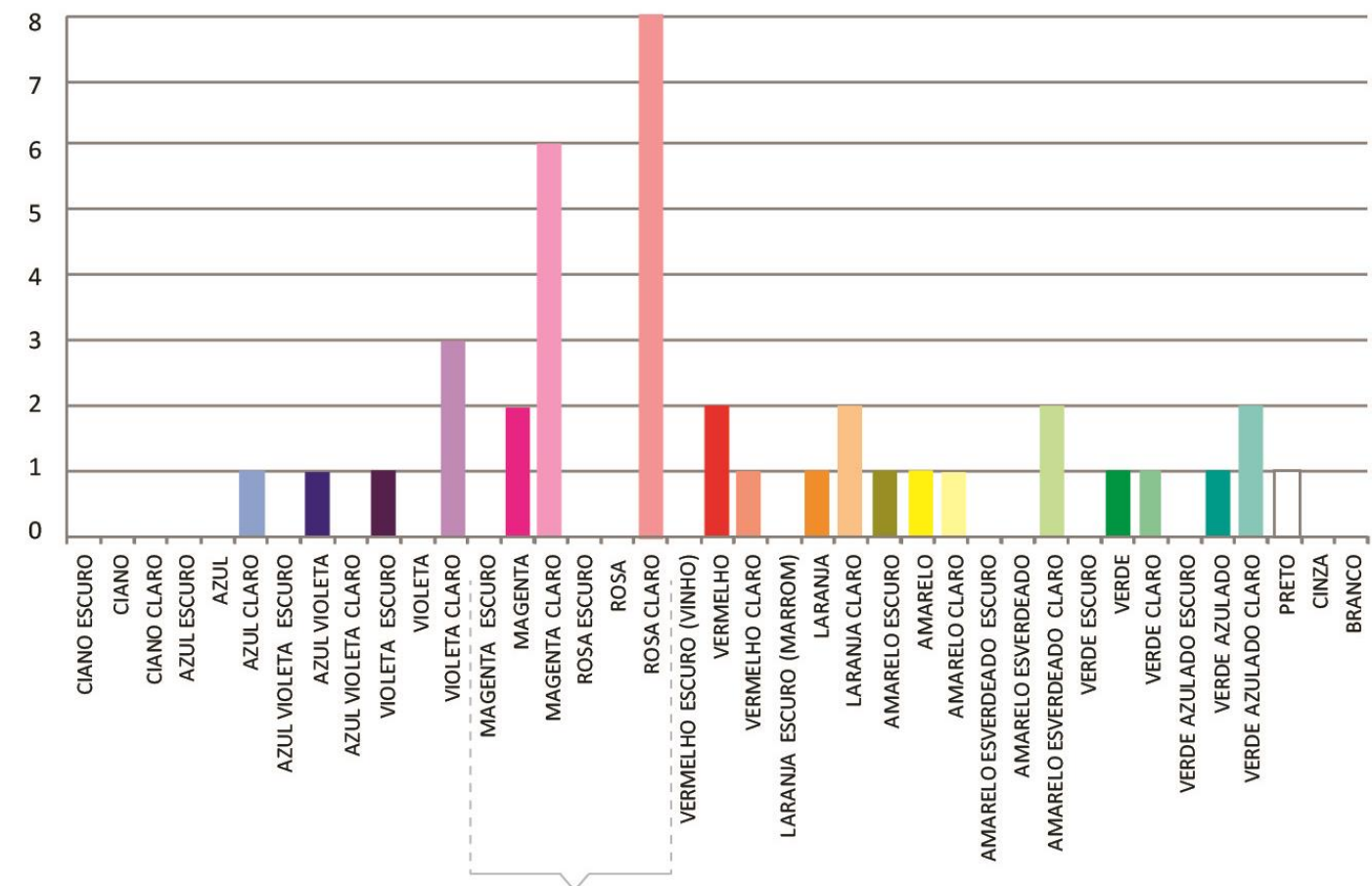

16 menções aos matizes rosados

Figura 12: As cores indicadas para o perfume floral (Floratta in Rose). Ordenação das cores por claridades.

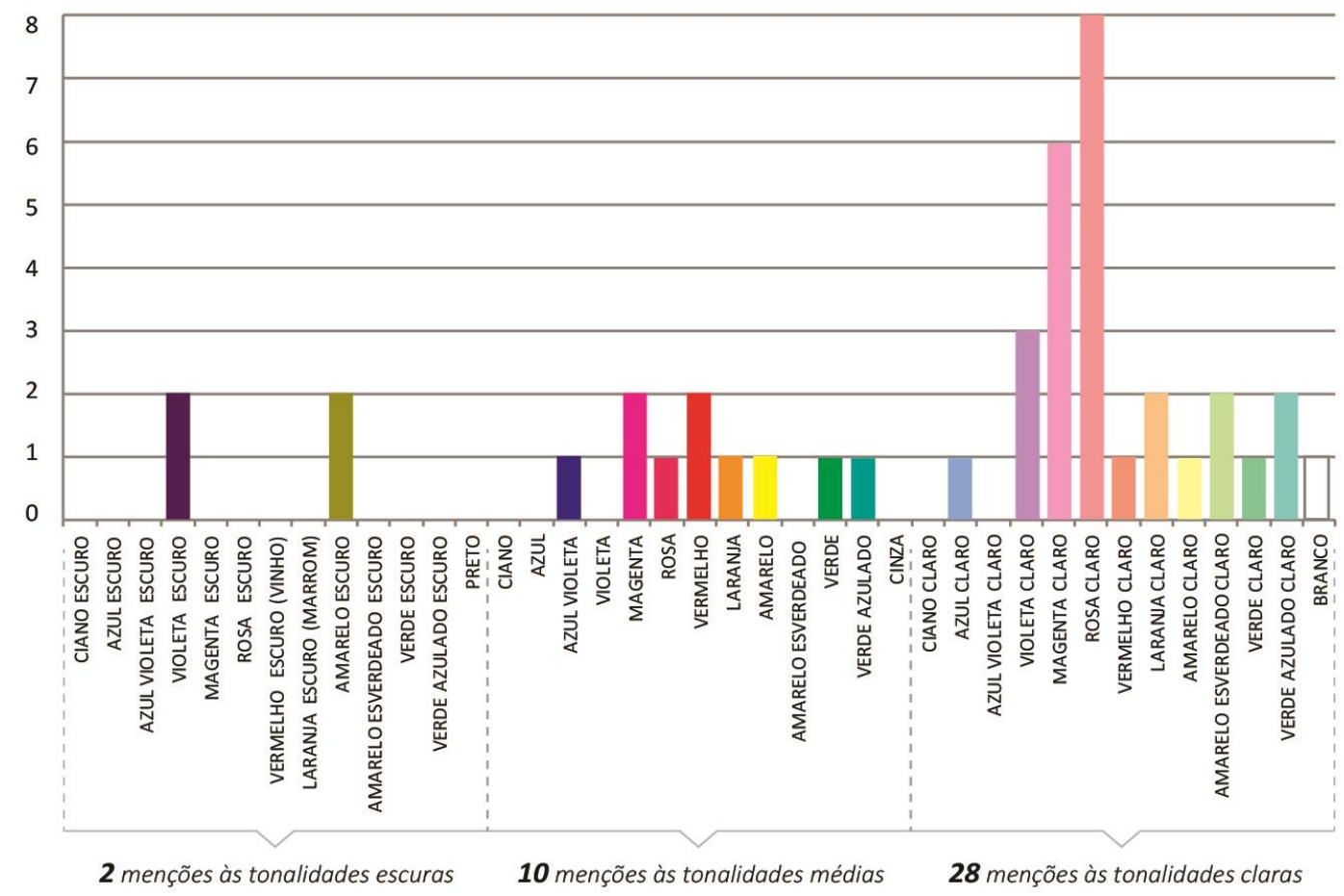

Figura 13: Palavras associadas ao perfume floral (Floratta in Rose).

Anais do 9 Congresso Internacional de Design da Informação | CIDI 2019 
Silva, C.A.P. I O cheiro como informação no design de embalagens: um estudo de produtos fragrantes.

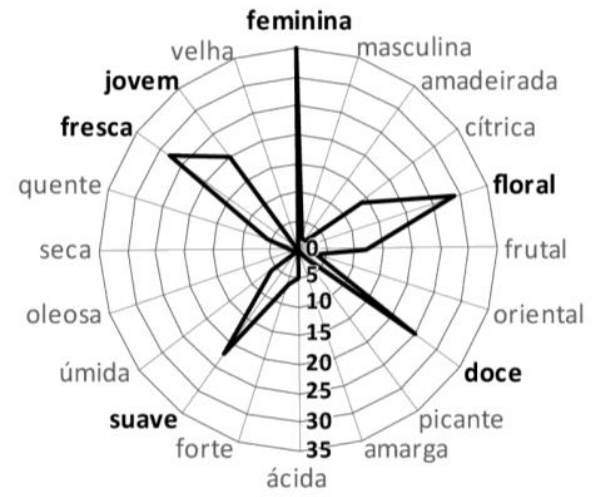

Perfume B -Floral - Grupo 1

\begin{tabular}{|c|c|}
\hline feminina & 35 \\
\hline masculina & 2 \\
\hline amadeirada & 2 \\
\hline citrica & 14 \\
\hline floral & 29 \\
\hline frutal & 12 \\
\hline oriental & 3 \\
\hline doce & 25 \\
\hline picante & 2 \\
\hline amarga & 0 \\
\hline
\end{tabular}

\begin{tabular}{|c|c|}
\hline ácida & 5 \\
\hline forte & 6 \\
\hline suave & 22 \\
\hline úmida & 6 \\
\hline oleosa & 0 \\
\hline seca & 1 \\
\hline quente & 6 \\
\hline fresca & 28 \\
\hline jovem & 20 \\
\hline velha & 0 \\
\hline
\end{tabular}

Com relação às associações dos cheiros às formas destacamos os resultados do experimento com o perfume Free, da família de cítricos. As formas apontadas para esse cheiro se apresentam tal como questionado na fase de levantamento bibliográfico, se o perfume cítrico seria relacionado às formas angulares assim como o cheiro cítrico do limão na pesquisa de Hanson-Vaux et. al (2013). Das respostas obtidas, $77,8 \%$ dos frascos se encontram na categoria de pontiagudos, assim como $60 \%$ das tampas selecionadas. A seguir apresentamos gráficos de frascos e tampas selecionados, seguidos de três figuras que apresentam as combinações entre as tampas e os três frascos mais selecionados pelos participantes.

Figura 14: Frascos escolhidos para o perfume cítrico (Free).

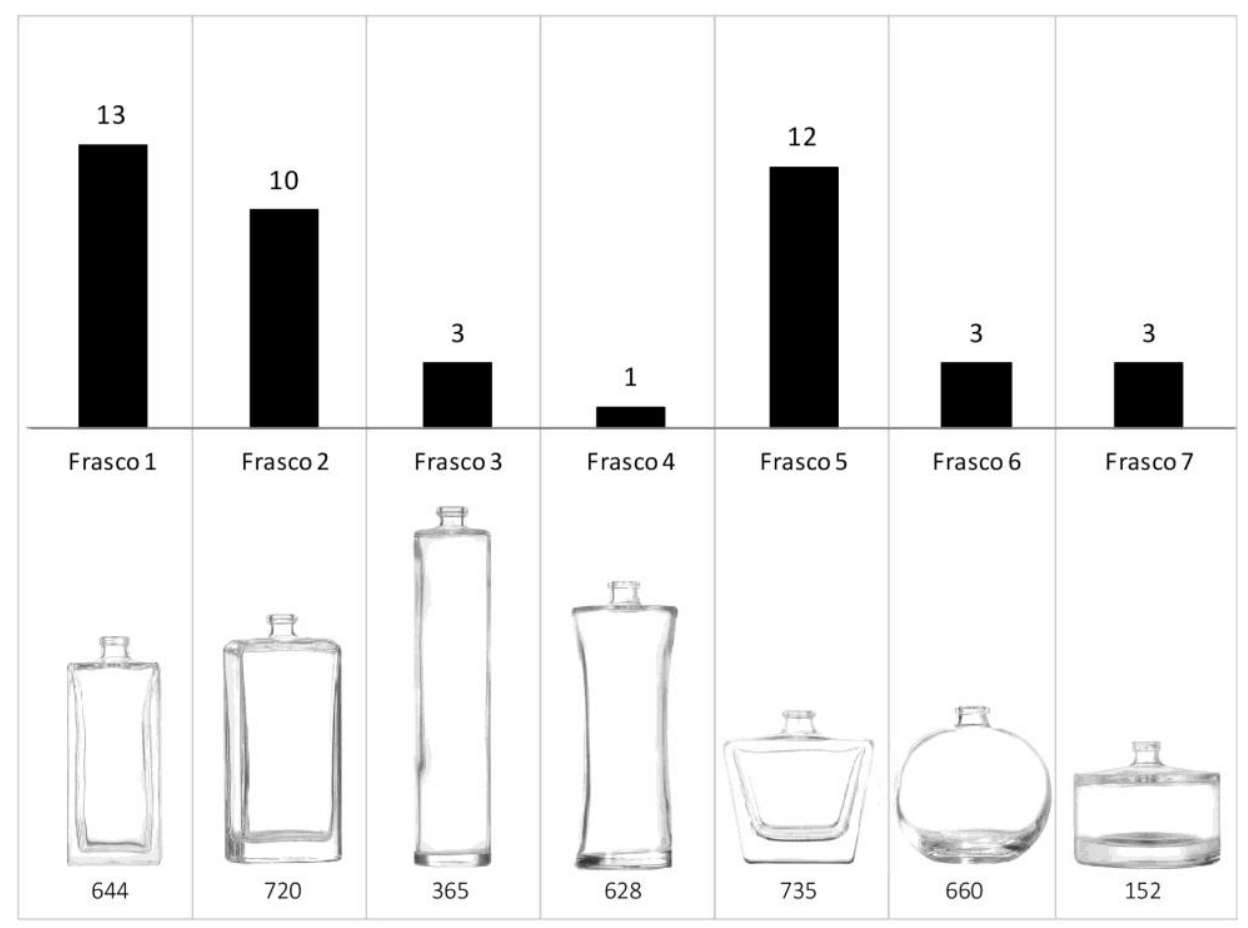

Figura 15: Tampas escolhidas para o perfume cítrico (Free). 
Silva, C.A.P. | O cheiro como informação no design de embalagens: um estudo de produtos fragrantes.

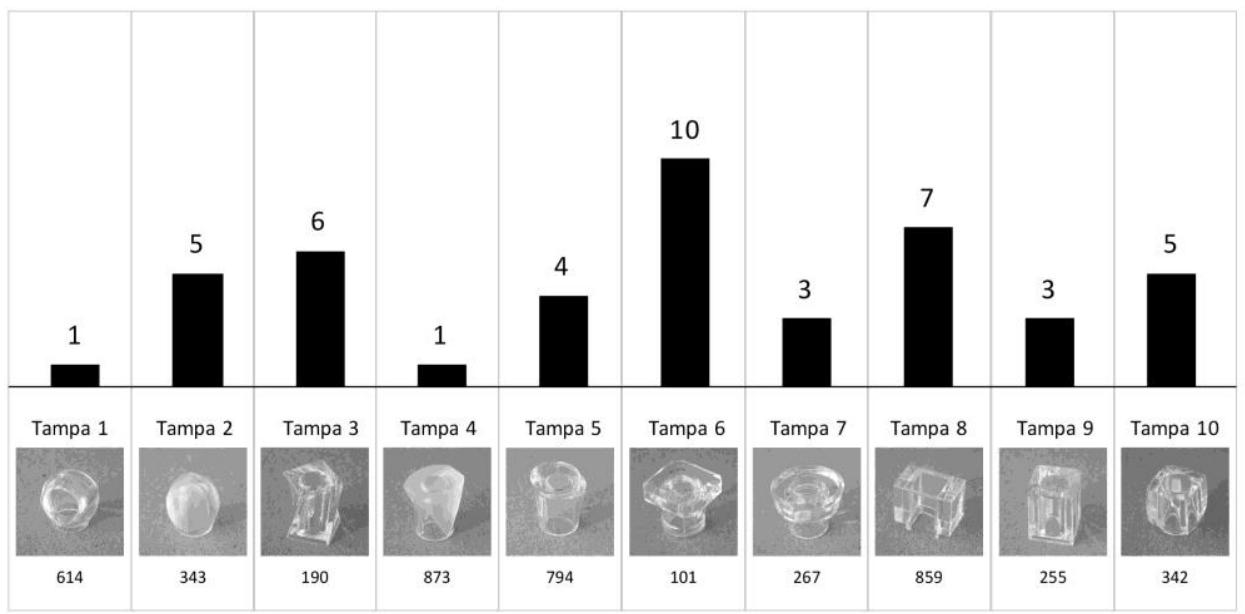

Figura 16: Combinações de tampas sugeridas para frasco 1 (n. 644).

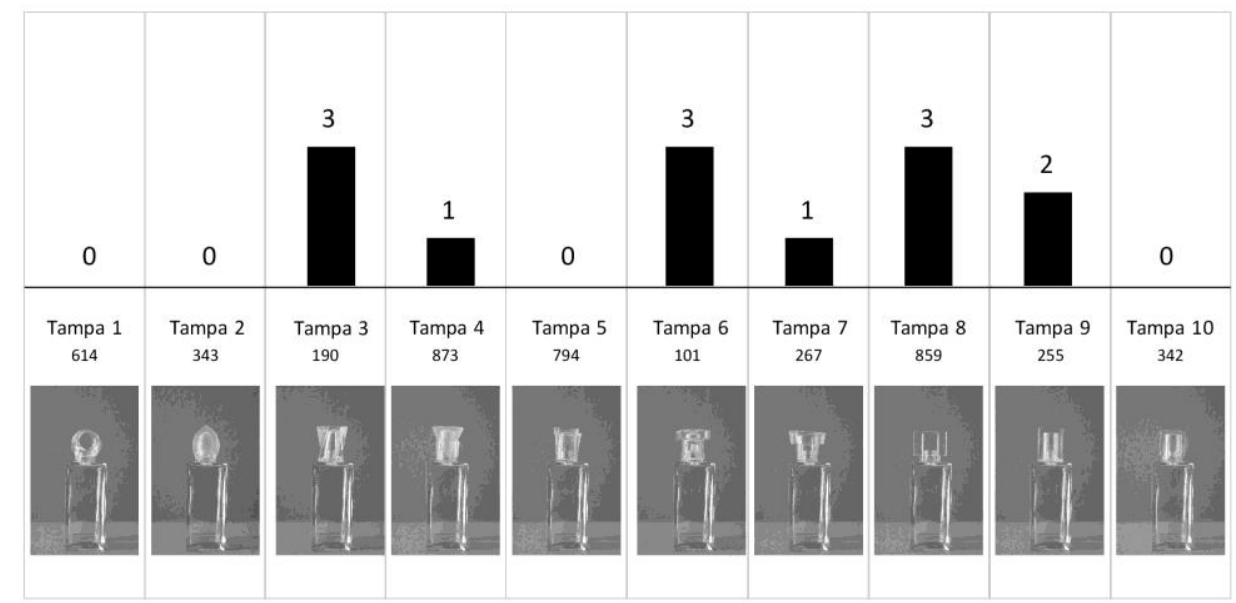

Figura 17: Combinações de tampas sugeridas para frasco 5 (n. 735).

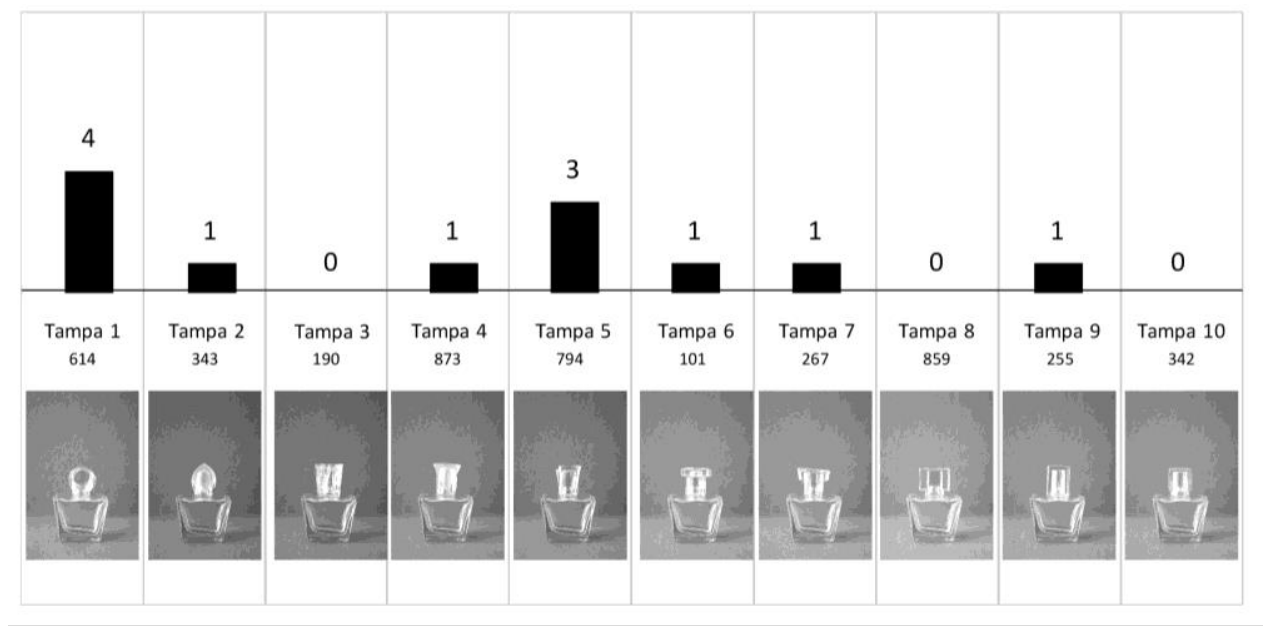

Anais do 9 Congresso Internacional de Design da Informação | CIDI 2019 
Silva, C.A.P. I O cheiro como informação no design de embalagens: um estudo de produtos fragrantes.

Figura 18: Combinações de tampas sugeridas para frasco 2 (n. 720).

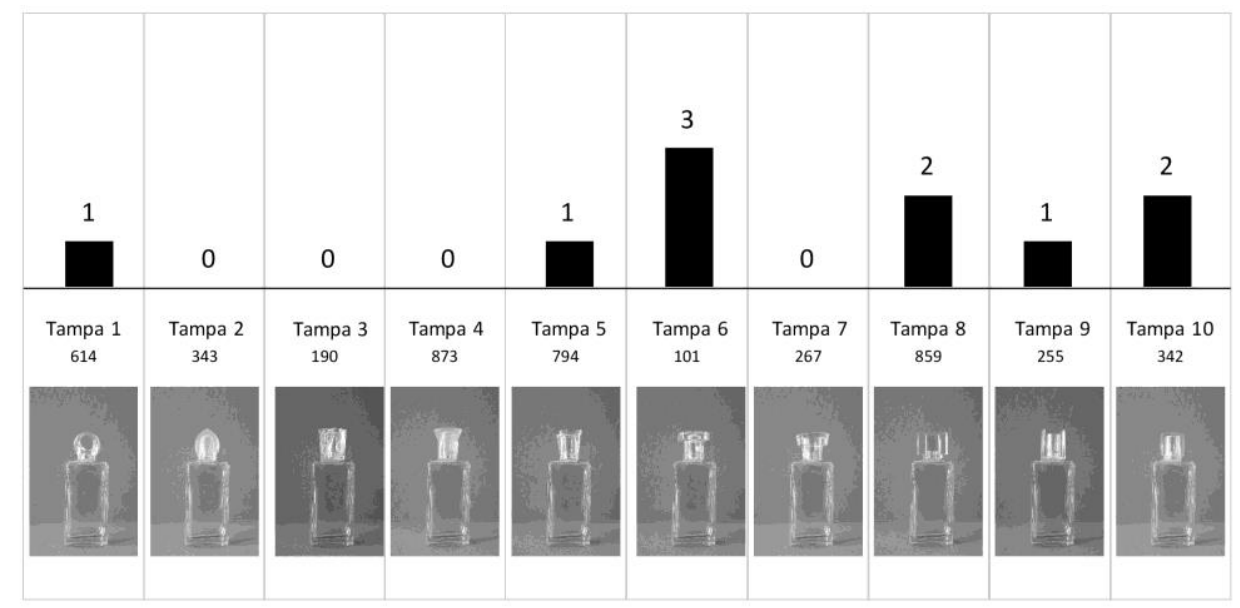

\section{Considerações finais}

Mediante resultados obtidos no levantamento bibliográfico e na realização dos experimentos sensoriais, concluímos a importância da integração entre sentidos. Com relação ao olfato, ressaltamos que apesar da negligência dada a esse sentido por nós seres humanos ao longo dos anos de nossa trajetória evolutiva, o cheiro é uma valiosa informação da qual podemos nos apropriar como designers. No que diz respeito à função que uma embalagem possui de informar sobre o que ela contém, embalagens de perfume estariam, portanto, encarregadas de traduzir os efeitos que a fragrância em questão pretende evocar. Nesse caso, o designer de embalagem deveria compreender melhor as informações que um cheiro pode carregar bem como os significados que as pessoas a eles atribuem. Dessa forma, seriam capazes de representá-los visualmente com mais eficácia e assim estabelecer uma melhor comunicação com o consumidor. Mesmo porque, neste segmento de produtos, a fragrância é um aspecto de escolha no momento da compra. Por isso, argumentamos que um projeto de embalagens para perfumes, que busque a máxima eficiência, deve se fundamentar nas de correspondências multissensoriais.

\section{Agradecimento}

Agradeço às instituições de fomento FAPERJ (2010 a 2011), CAPES (2012) e FAPESP (2014 a 2015) pelas bolsas de estudo para mestrado e doutorado, tendo viabilizado a execução de grande parte dessa pesquisa.

\section{Referências}

ABIHPEC. (2017). Panorama do Setor de Higiene Pessoal, Perfumaria e Cosméticos. Disponível em: <https://abihpec.org.br/publicacao/panorama-do-setor-2016-2/>. Acesso em 25 Jan. 2017.

Demattè, M. L., Sanabria, D., \& Spence, C. (2006). Cross-modal associations between odors and colors. Chemical Senses, 31, pp. 531-538.

Gilbert, A. N., Martin, R., \& Kemp, S. E. (1996). Cross-modal correspondence between vision and olfaction: the color of smells. American Journal of Psychology, 109(3), pp. 335-351.

Hanson-Vaux, G., Crisinel, A.-S., \& Spence, C. (2013). Smelling Shapes: Cross-modal correspondences between odors and shapes. Chemical Senses, 38(2), pp. 161-166. 
Silva, C.A.P. | O cheiro como informação no design de embalagens: um estudo de produtos fragrantes.

Haverkamp, M. (2013). Synesthetic design:a handbook for a multi-sensory approach. Birkhäuser: Switzerland.

Ishihara, S. (1972). The series of plates designed as a test for colour-blindness. Tokyo: Kanehara Shuppan.

Joutsela, M. (2010). Multisensory persuasion and storytelling through packaging Design. In 17th IAPRI World Conference on Packaging. IAPRI - International Association of Packaging Research Institutes.

Kim, Y. J. (2008). The effect of color design on fragrance association. Proceedings of 6 th Design and Emotion Conference. Hong Kong.

Lindstrom, M. (2012). Brandsense: a marca multissensorial. Porto Alegre: Bookman.

Macpherson, F. (2011). Cross-modal experiences. Proceedings of the Aristotelian Society, 111(3), pp. 429-468.

Malnic, B. (2008). O cheiro das coisas - o sentido do olfato: paladar, emoções e comportamentos. Rio de Janeiro: Vieira \& Lent.

Moeran, B. (2011). The Colours of Smell: Perfume Advertising and the Senses. Paper presented at The 110th Annual Meeting of the American Anthropological Association, Montreal, Canada.

Morrot, G., Brochet, F., \& Dubourdieu, D. (2001). The Color of Odors. Brain and Language, 79, pp. 309-320.

O Boticário. Disponível em: <http://www.boticario.com.br/perfumaria/>. Acesso em 25 Jan. 2017.

Plaza, J. (1987). Tradução intersemiótica. São Paulo: Perspectiva.

Rader, C. M., \& Tellegen, A. (1987). An investigation of synesthesia. Journal of Personality and Social Psychology, 52(5), pp. 981-987.

Silva, C. A. P. (2012). Perfume, história e design: o papel das embalagens no mercado brasileiro de perfumaria. Dissertação (Mestrado). Rio de Janeiro, Rio de Janeiro: Universidade do Estado do Rio de Janeiro.

Silva, C. A. P., \& Mazzilli, C.T.S. (2014). The colors of the smells: the influence of culture and society in the visual design of packaging of perfume. In 9th International Committee for Design History and Design Studies: Tradition, Transition, Trajectories: Major or Minor Influences? Aveiro: UA Editora. v. 1. pp. 373-378.

Spector, F., \& Maurer, D. (2012). Making sense of scents: the colour and texture of odours. Seeing and Perceiving. Koninklijke Brill NV, Leiden, 25, pp. 655-677.

Spence, C., \& Piqueras-Fiszman, B. (2012). The multisensory packaging of beverages. In Kontominas, M. G. (ed.), Food packaging: procedures, management and trends. Hauppauge, NY: Nova Science Publishers, pp. 187-233.

Süskind, P. (2001). Perfume: the story of a murderer. New York: Vintage.

Wolfe, J. M. et al. (2012). Sensation \& Perception (3rd Edition). Sunderland, MA: Sinauer Associates.

\section{Sobre a autora}

Camila Assis Peres Silva, PhD, UFCG, Brasil <camila.assis@ufcg.edu.br> 